\title{
Students' Error in Lexical Meaning in Communication through Conversation in the Classroom
}

\author{
Andyka Yulia Adha \\ English Applied Linguistics \\ Postgraduate School \\ State University of Medan \\ Medan, Indonesia \\ dyka adha03@yahoo.co.id \\ Ayu Widyaningtyas \\ English Applied Linguistics \\ Postgraduate School \\ State University of Medan \\ Medan, Indonesia \\ ayuwidyaningtyas25@gmail.com
}

\begin{abstract}
In teaching practice in school, there is unintelligible pronunciation of some students. Intelligible pronunciation is essential during a listening process, clear and correct pronunciation makes a conversation more comfortable for both the speaker and the listener and even helps to avoid misunderstanding. Lexical relations include hyponyms, meronyms, homonyms, synonyms, and antonyms. While meaning properties include meaningfulness, ambiguity, redundancy, anomaly, and contradictory. Those topics will be analyzed in this paper. From the observation conducted by the researcher indicated that homophone barrier was the dominant barrier happened in the conversation between teacher and students. It was fifty percent $(50 \%)$ while the rest was thirty four percent $(34 \%)$ in homonym barriers and sixteen percent in homograph barriers. The homophone barrier often occured dominantly, it was caused there were some certain words n English had a same pronunciation. Moreover the students interpreted it differently
\end{abstract}

Keywords—students' error, lexical meaning, communication

\section{INTRODUCTION}

English is considered as the global communicative language in our present world. Similarly in Bangladesh, learning English language is given sufficient emphasis nowadays to develop its people's communicative competence through the basic skills- reading, writing, speaking and listening. However, learning proper pronunciation is the most difficult part, and in this regard Maniruzzaman (as cited in Mumeneen, 2011) stated that, pronunciation is hardly given enough importance while teaching and learning English at the primary.
Many schools or educational institutions are giving importance on learning proper pronunciation nowadays, whereas Nath et al. (2011) stated that, Sylhet division is still a low performing region in terms of education (Exploring Low Performance in Education: The Case of Sylhet Division, para. 3). Although some schools of urban areas in Sylhet division are doing really good in providing quality English language learning based on the rate of primary and secondary education completers, the sub-urban areas lag much behind than the national average. The students of these schools lack English

speaking efficiency due to lack of practice as well as their poor pronunciation skills.

Despite the existence of thousands of languages all around the world millions of people speak English as their mother tongue. Moreover, there are millions of others who use English either as their second language or an international language when communicating with people all around the world.

In teaching practice at a secondary school that was found unintelligible pronunciation of some students. Intelligible pronunciation is essential during a listening process, clear and correct pronunciation makes a conversation more comfortable for both the speaker and the listener and even helps to avoid misunderstanding.

\section{STUDENT'S ERROR IN LEXICAL MEANING}

In this study the researcher was focused in students' error in lexical meaning through conversation in the classroom by looking for some barriers communication in pronunciation. 
Since the thesis study is concerned with pronunciation teaching, pronunciation as such must be defined first. Pronunciation is a way how sounds are articulated by speakers marking their social class, education and so forth. According to Dalton and Seidlhoffer there are two ways how pronunciation as a production of significant sounds can be characterized:

First, sound is significant because it is used as part of a code of a particular language. So we can talk about the distinctive sounds of English, French, Thai, and other languages. In this sense we can talk about pronunciation as the production and repetition of sounds of speech.

Second, sound is significant because it is used to achieve meaning in context of use. Here the code combines with other factors to make communication possible. In this sense we can talk about pronunciation with reference to acts of speaking (1994: 3). According to Horwitz (2001: 119), there is proof that classroom atmosphere rather than specific activities may decrease students' anxiety (e.g. Palacios, 1998). Palacios (1998) found that perceived teacher support had a strong correlation students' feelings of anxiety (Horwitz, 2

Teacher support was defined as the help and friendship the teacher was said to offer the students (ibid.).

Horwitz (2001: 121-122) notes that anxious learners simply have difficulty displaying the language competence they have attained, and if this is the case, language anxiety research may be a useful tool in explaining differential success in language learning and understanding frustration and discomfort in SLA. However, it is debatable whether language anxiety might affect speech production as such, or if it might be rather a symptom than the cause of the problems, because it is closely connected with, for example, social factors like fear of disrespect that might cause speech difficulties. The challenge is to determine the extent to which anxiety is a cause rather than a result of poor language learning or learning environments (Horwitz, 2001: 118).

\section{Nature of Homonyms}

In linguistics, a homonym is, in the strict sense, one of a group of words that share the same spelling and the same pronunciation but have different meanings (Wiley-Blackwell, 1999: 215). Thus, homonyms are simultaneously homographs (words that share the same spelling, irrespective of their pronunciation) and homophones (words that share the same pronunciation, irrespective of their spelling). The state of being a homonym is called homonymy. Examples of homonyms are the pair of "can" (being able to do something) and "can" (tin) and the pair of "right" (true) and "right" (the side of).

To simplify the discussion of homonyms, the researcher provides a comprehensive table dividing the various types of homonyms based on the explanation by James R. Hurford and Brendan Heasley (1983: 123).
Table 2.1. Various Types of Homonyms

\begin{tabular}{|c|c|c|c|}
\hline Term & Meaning & Spelling & Pronunciation \\
\hline Homonym & Different & Same & Same \\
\hline Homograph & Different & Same & Same or different \\
\hline Homophone & Different & $\begin{array}{l}\text { Same or } \\
\text { different }\end{array}$ & Same \\
\hline Heteronym & Different & Same & Different \\
\hline Heterograph & Different & Different & Same \\
\hline Polyseme & $\begin{array}{l}\text { Different but } \\
\text { related }\end{array}$ & Same & Same or different \\
\hline Capitonym & $\begin{array}{l}\text { Different } \\
\text { when }\end{array}$ & $\begin{array}{l}\text { Same } \\
\text { except for }\end{array}$ & Same or different \\
\hline & Capit & $\begin{array}{l}\text { Capitalizat } \\
\text { ion }\end{array}$ & \\
\hline
\end{tabular}

The explanations for each term are:

1. Homographs (literally "same writing") are usually defined as words that share the same spelling, regardless of how they are pronounced. If they are pronounced the same then they are also homophones (and homonyms) - for example, bark (the sound of a dog) and bark (the skin of a tree). If they are pronounced differently then they are also heteronyms - for example, bow (the front of a ship) and bow (a type of knot).

2. Homophones (literally "same sound") are usually defined as words that share the same pronunciation, regardless of how they are spelled. If they are spelled the same then they are also homographs (and homonyms); if they are spelled differently then they are also heterographs (literally "different writing"). Homographic examples include rose (flower) and rose (past tense of rise). Heterographic examples include to, too, two, and there, their, they're.

3. Heteronyms (literally "different name") are the subset of homographs (words that share the same spelling) that have different pronunciations (and meanings). That is, they are homographs which are not homophones. Such words include desert (to abandon) and desert (arid region); row (to argue or an argument) and row (as in to row a boat or a row of seats - a pair of homophones). Heteronyms are also sometimes called heterophones (literally "different sound").

4. Polysemes are words with the same spelling and distinct but related meanings. The distinction between polysemy and homonymy is often subtle and subjective, and not all sources consider polysemous words to be homonyms. Words such as mouth, meaning either the orifice on one's face, or the opening of a cave or river, are polysemous and may or may not be considered homonyms.

5. Capitonyms are words that share the same spelling but have different meanings when capitalized (and may or may not have different pronunciations). Such words include polish (to make shiny) and Polish (from Poland); March (organized, uniformed, steady and rhythmic walking forward) and March (the third month of the year in the Gregorian calendar). However, both polish and March at the beginning of sentences still need to be capitalized. 


\section{METHODOLOGY}

For knowing some barriers in students English pronunciation, this study was intended to analyze pronunciation errors of vowel sounds in English words made by the students. In this research, the writer decided that the design of this proposed study was descriptive qualitative research. Mardalis explained that descriptive research is to describe or to get information about the current condition of certain objects. Therefore, it included describing, taking notes, analyzing, and interpreting the existing facts. This research is designed to identify the kind of vowels sound pronounced errors and the sources of vowels sound pronounced incorrectly by the students. The data was form the transcription in conversations between the students and teacher by observing students' error in transmitted and understanding of teacher's instruction in teaching learning process during 5 days. The source of the data was from students in Budi Agung Senior high school in the first grade. As a sample, by using random sampling technique, this study was intended in X-1 which consisted of 25 students. The technique of data collection is collected by using documentary technique, According to Thomas, Nelson, and Stephen (2015: 58) documentary technique is one of the part in observation by recording the data from transactional interaction. In which, only the data support research question are taken. The data of this research is taken from the record of transactional interaction in conversation between the students and teacher during teaching learning process in explaining descriptive text. The data was taken through some steps which are consisted of Recording and transcribing.

1. The data is taken by recording transactional interaction between students and teacher during teaching learning process

2. Transcribe the transcription of conversation between students and teacher during teaching learning process in explaining descriptive.

In conclusion, the teacher dominantly used casual style in communicating to students in English course class. Based on the result of this research, it was expected to students of linguistics especially for language and communication can attentively focus on the analysis of language styles and other researchers to widen their horizon about the benefit of doing research whenever they want to prove their intended purposed in research area. The data are analyzed based on interactive model proposed by Miles, Huberman, and Saldana (2014) with three phases of data analysis. The data collected in this research are raw data. Therefore, to make them meaningful, there are some steps to analyze it.

The steps of analyzing data used are:

\section{Identifying errors}

Here, the researcher labelled by underlining students' error in transcription of the conversation between students and teacher while the students answered some questions were given by the teacher.

\section{Classifying errors}

Form the written data of the students' error in transcription of the conversation between students and teacher, and the error was categorized as semantic barrier in homophone, homograph and homonym.

\section{Quantifying errors}

In this step, the researcher calculated the error in order to know how frequent these errors made by the first year students of SMA Budi Agung Medan. In this case, the writer presented it in term of percentage, and the writer used formula Levin and Fox quoted by Sugiatun.

$$
\sum={ }_{\mathrm{N}}^{\mathrm{n}(\mathrm{x})}
$$

Where: $\sum=$ the percentage of pronunciation errors $\mathrm{n}(\mathrm{x})=$ the total of each pronunciation errors $\mathrm{N} \quad=$ the total of all pronunciation errors

This formula is only used to know the percentage, but overall this study uses qualitative approach.

\section{Drawing conclusion}

The last step drew conclusion based on the analysis. In this step, the researcher has to make a valid conclusion in the form of a brief description of the errors after interpreting those errors. Finally, the writer analyzed data from observation. Then, the writer drew conclusion.

\section{RESULT AND CONCLUSION}

The result of the research showed that the conversation between students and teacher was found that 50 percent barries in homophones while 16 percent barriers in homograph and in addition 34 percent barrier in homonym. The transcription of students and teacher conversation during 5 days teaching learning process in barriers homophones as follows.

Teacher : "What is your favourite snake?"

Student 1: "My favourite snake is phyton"

Student 2: "My favourite snack is Chitatio, Miss"

From the conversation above, it could be shown that student 1 concluded the questions of "snake" form the teacher as a snake itself meanwhile the student 2 interpreted the word "snake" form the teacher as a snack. It could be concluded that many students had homophone barrier in daily conversation during teaching and learning process when the teacher explained about descriptive text about animal.

Teacher : "What do you like from sheep?" sailorman"

Student 1: "I like ship because my dad is a

Student 2: "I like the sheep because it has a smooth fur"

From the conversation above, it could be shown that student 1 concluded the question of "sheep" from the teacher as ship meanwhile the student 2 interpreted the word "sheep" from the teacher as a sheep itself. It could be concluded that 
many students had barrier in daily conversation in homophones.

Teacher : According to you, is the ant is horrible?"

Student 1:" Yes, my aunt is horrible because she is always angry with me"

Student 2:" Yes, because the ant has a hard bite and it hurts me".

Student 3 :" Yes, because the ant likes to eat my candy and I dont like it"

From the conversation above, it could be said that student 1 concluded the question of "ant" from the teacher as aunt, while student 2 interpreted the question of "ant" from the teacher as ant itself and student 3 interpreted the question of "ant" as ant itself.

The transcription of students and teacher conversation during 5 days teaching learning process in barriers homonym as follows.

Teacher :"Have you ever about tale?"

Student 1: "Yes, Mam, Monkey has a tail"

Student 2: "Yes, I have many tale stories"

From the conversation between teacher and student, it showed that student 1 answered the question of "tale" from the teacher as a tail which meant part of the body of animal. Student 2 interpreted the question of "tale" from the teacher as a correct meaning suitable what the teacher asked to the students, it was a legend story. It can be said that there were homonym barriers in daily conversation during teaching and learning process.

Teacher :"Do you deer?"

Student 1:" Oh Miss, I wanna you call me dear.

Student 2:"Please, Sherin, our teacher asks about deer, it is one of animal. Miss. I know about deer".

From the conversation between teacher and student, it showed that the student 1 answered the question of "deer" from the teacher as dear while student 2 interpreted the question of "deer" as a correct meaning suitable what the teacher asked, it was deer, it was a kind of animal.

The transcription of students and teacher conversation during 5 days teaching learning process in barriers homograph as follows;

Teacher : "My student, when do you see a bat?

Student 1 :"I see a bat in the dark, Miss"

Student 2 :"I ever saw many bats in my storehouse, Miss. they only fly at night with a dark condition"

Student 3: But Miss, My dad bought me a bat in my seventeen birthday party. I can play it for playing baseball”.'

From the conversation above, it indicated that student 1 interpreted the question of "bat" as ta correct meaning suitable with what the teacher asked to the students while student 2 answered the question of "bat" as a bat itself, it was a kind of animal liked to fly out at night. In the other hand, student 3 concluded the question of "bat" as a equipment in playing baseball. From the answer uttered by the student 3 indicated that there was a homograph barrier.

From the observation conducted during 5 days in Budi Agung Senior high school especially for the first grade students showed that there were barriers communication in daily conversation between teacher and students especially in descriptive material, they were homophone barrier, homonym barrier and also homograph barrier. From the observation conducted by the researcher indicated that homophone barrier was the dominant barrier happened in the conversation between teacher and students. It was fifty percent while the rest was thirty four percent in homonym barriers and sixteen percent in homograph barriers. The homophone barrier often occured dominantly, it was caused there were some certain words $\mathrm{n}$ English had a same pronunciation. Moreover the students interpreted it differently.

\section{REFERENCES}

[1] Adult Migrant English Program Research. (2002, October). What is pronunciation. (No.1)

[2] Barman, B. C. (2009). Problems faced by Bengali learners in English pronunciation. In P. Ostalski (Eds.), International conference on native and non-native accents of English.

[3] Catford, John, Cunnison. A Practical Introduction to Phonetics. New York: Oxford University Press, 1992.

[4] Dalton, Christiane and Barbara Seidlhofer. Pronunciation. Oxford:Oxford University Press, 1994.

[5] Derwing, M. T., \& Munro, J. M. (2005). Second language accent and pronunciation teaching: A research-based approach. Teachers of English to Speakers of Other Languages, Inc. (TESOL), 39, 379-397.

[6] Farhana, T. (2010, May). Profile of some schools in Sylhet. Star Campus, 2(18).

[7] Hancock, M. (2003). English pronunciation in use. Cambridge: Cambridge University Press.

[8] Hasan, S. M. M. (2013). Bangla-specific study of English monophthongs. BRAC University Journal, $X$, 41-47.

[9] Hoque, M. A. (2011). The influence of the local varieties on the sound patterns of English: A case study of Bangladeshi tertiary students. IIUC Studies, 7, 197-220.

[10] Jenkins, Jenifer. The Phonology of English as an International Language. Oxford: Oxford University Press, 2000.

[11] Kelly, Gerald. How to Teach Pronunciation. Harlow: Longman, 2002.

[12] Roach, Peter. English Phonetics and Phonology. Cambridge: Cambridge University Press, 1992.

[13] Roach, Peter. Introducing Phonetics. London: Penguin English, 1992.

[14] Stern, Hans, Heinrich. Issues and Options in Language Teaching. Oxford: Oxford University Press, 1992. 